\title{
Is it necessary to control the level of estrogen receptor $\alpha$ and $\beta$ activation in postmenopausal hormone replacement therapy in order to achieve the optimal outcome? (Review)
}

\author{
BAO TING ZHU \\ Department of Pharmacology, Toxicology and Therapeutics, School of Medicine, \\ University of Kansas Medical Center, Kansas City, KS 66160, USA
}

Received November 2, 2007; Accepted November 30, 2007

\begin{abstract}
Endogenous estrogens exert an array of biological actions on women, many of which are mediated by the estrogen receptors (ERs) $\alpha$ and $\beta$. Results from our recent studies suggest that the human ER $\alpha$ and ERß systems are differentially activated under different physiological conditions. In non-pregnant young women, the ER $\alpha$ system is preferentially activated over the ERß system, mainly by estrone (E1) and its major oxidative metabolite, 2-hydroxy-E1. These two estrogens are among the quantitatively major estrogens present in young women, and have approximately 4-fold preferential activity for ER $\alpha$ over ERß. During pregnancy, however, there is a preponderance of activation of ERß over $\mathrm{ER} \alpha$ conferred by various pregnancy estrogens such as estriol and other $D$-ring derivatives of $17 ß$-estradiol (E2). These estrogens have an up to 18 -fold preference for binding to ERß than for $E R \alpha$, and some of them are produced in unusually large quantities. Given this new information, it is hypothesized that the estrogens ideal for female hormone replacement therapy (HRT) would be those which produce a hormonal condition mirroring that found in non-pregnant young women rather than in pregnant women. Endogenous estrogen derivatives, such as the sulfated conjugates of E1, may be among the ideal candidates for achieving this clinical purpose. In comparison, Premarin, the most commonly-used HRT containing a mixture of conjugated estrogens isolated from pregnant mare's urine, is less suitable because several of its estrogenic components can produce a strong preferential overstimulation of the human ERß signaling system.
\end{abstract}

Correspondence to: Dr Bao Ting Zhu, Department of Pharmacology, Toxicology and Therapeutics, University of Kansas Medical Center, MS-1018, Room KLSIC-4061, 2146 W. 39th Avenue, Kansas City, KS 66160, USA

E-mail: btzhu@kumc.edu

Abbreviations: ER, estrogen receptor; ER $\alpha$ and ERß, estrogen receptor $\alpha$ and $B$ subtypes; E1, estrone; E2, 17ß-estradiol; $\mathrm{OH}$, hydroxy; RBA, relative binding affinity

Key words: hormone replacement therapy, estrogen receptor $\alpha$ and $\beta$ subtypes, Premarin, estrogens

\section{Contents}

1. Introduction

2. Differences in the composition and quantity of endogenous estrogens produced in pregnant and non-pregnant women

3. Differences in the biological activity of pregnancy and non-pregnancy estrogens

4. Biological activity of estrogens contained in Premarin

5. Which estrogens are ideal for postmenopausal hormone replacement therapy?

6. Concluding remarks

\section{Introduction}

Female hormone replacement therapy (HRT), also commonly called menopausal hormone therapy, is a hormonal treatment for peri- or post-menopausal women undertaken to reduce the discomfort and health problems associated with diminished circulating ovarian hormones (namely, estrogens and progesterone). HRT usually provides a low dose of an estrogen (or a mixture of estrogens), often in combination with a progestin. In the past few decades, the most commonly-used estrogen treatment for HRT has been Premarin, which consists of a mixture of mostly sulfated estrogens isolated from pregnant mare's urine. The hormonal activity of these conjugated estrogens in vivo results from their enzymatic hydrolysis and releases biologically active estrogens.

Until a few years ago, the generally-held scientific belief was that 'an estrogen is an estrogen', i.e., that all estrogens exert similar pharmacological actions on the body. However, this dogmatic view has gradually changed over the past decade due, in large part, to the emergence of the following body of new knowledge.

First, it has become known that multiple subtypes of estrogen receptor (ER) exist $(1,2)$. These have very different tissue and cell distribution in the body, and both overlapping and completely different biological functions in different target tissues or cells $(1,2)$.

Second, studies have shown that certain ER agents, such as tamoxifen and raloxifene, can selectively modulate the function of ERs in different target tissues/cells in different ways, serving as ER antagonists in one tissue (such as the breast) but as weak agonists in another (such as bone) $(3,4)$. 
Third, certain endogenous estrogens and their metabolic derivatives have very different binding affinities for human $\mathrm{ER} \alpha$ and ERß (discussed below) (5). Furthermore, some of the estrogen metabolites that are often selectively formed in certain target cells or formed under unique physiological or pathological conditions can exert very different biological functions that are not necessarily shared by their parent hormone 17ß-estradiol (E2) (6-8).

Recently, we systematically compared the activity of a large number of endogenous estrogen metabolites, including many of those contained in Premarin, relating to human $\mathrm{ER} \alpha$ and ERß (5). We found that while E2 (perhaps the bestknown endogenous estrogen) has nearly the highest, and almost identical, binding affinity for human $\mathrm{ER} \alpha$ and $\mathrm{ER} \beta$, many of its metabolites have widely different preferences for human ER $\alpha$ and ERß activation (5). In addition, it should be noted that the predominant estrogens in pregnant women are very different from those present in non-pregnant ones, and that these estrogens have widely different preferences when it comes to the activation of human ER $\alpha$ and ERß. Based on this information, a new concept is proposed here, one which suggests that differential activation of ER $\alpha$ over ER $\beta$ may be a crucial factor in achieving optimal clinical outcome in postmenopausal HRT. Recommendations are made as to which types of estrogens would be ideal for human use in menopausal HRT.

2. Differences in the composition and quantity of endogenous estrogens produced in pregnant and non-pregnant women

A large number of endogenous estrogen derivatives are known to be present in humans. Studies have been conducted in the past to determine the human urinary excretion of various estrogens (mostly as conjugates) as a global indicator of the bio-synthesis and metabolism of endogenous estrogens in vivo $(9,10)$. Based on our recent data (Table I), it is estimated that the total daily amount of various urinary estrogens excreted from a late-stage pregnant woman is 2-3 orders of magnitude higher than the amount excreted by a non-pregnant woman of the same age group. In addition, the composition of urinary estrogens in pregnant and non-pregnant women is widely different. Representative profiles of various endogenous estrogens found in the urine of pregnant and non-pregnant young women are summarized in Table I.

In the urine samples obtained from non-pregnant young women, the conjugated forms of 2-OH-E1, followed by $16 \alpha-$ $\mathrm{OH}-\mathrm{E}_{2}\left(\mathrm{E}_{3}\right), 16 \alpha-\mathrm{OH}-\mathrm{E}_{1}$ and $\mathrm{E}_{1}$ (estrone), are the predominant estrogens. The amount of $\mathrm{E}_{2}$ and its major metabolites 2-OH$\mathrm{E}_{2}$ and 2-methoxy-E2 was much less than that of $\mathrm{E}_{1}$ and its corresponding metabolites. The relative composition of the various estrogens in circulation is believed to be comparable to that of urine. The presence of higher levels of E1 than of E2 in non-pregnant women is largely attributable to high levels of oxidative 17ß-hydroxysteroid dehydrogenase (17ß-HSD), which catalyzes the facile conversion of $\mathrm{E}_{2}$ to $\mathrm{E}_{1}$. The conversion of $\mathrm{E}_{1}$ to 2-hydroxy-E1 or $\mathrm{E}_{2}$ to 2-OH-E2 is catalyzed by cytochrome P450 enzymes (11-14) and by subsequent $O$-methylation, which forms $2-$ methoxy- $\mathrm{E}_{1} / \mathrm{E}_{2}$ is catalyzed by catechol-O-methyltransferase (COMT) $(7,15)$.
There is a drastic change in endogenous estrogen composition during pregnancy. E3 becomes the predominant estrogen and is produced in unusually large quantities. The daily amount of this estrogen (in its conjugated form) released into the urine of late-stage pregnant women is 200-1000 times higher than that of any of the quantitatively major estrogens produced in non-pregnant women. Notably, several other $D$-ring estrogen derivatives, such as 17-epi-E3, 16-epi-E3, 16,17-epi-E3 and estetrol $\left(15 \alpha-\mathrm{OH}-\mathrm{E}_{3}\right)$, are also produced in readily-detectable quantities during the late stages of pregnancy. These $D$-ring derivatives are usually only present in low or undetectable levels in non-pregnant young women. Similar results have been reported in previous studies $(11,12)$.

In summary, although $\mathrm{E}_{2}$ is perhaps the best-known endogenous estrogen in humans, it is not the predominant estrogen produced in the body of pregnant women or of nonpregnant women. The major endogenous estrogens that are produced in non-pregnant women are vastly different in quantity and also in composition from those produced in pregnant women.

\section{Differences in the biological activity of pregnancy and non-pregnancy estrogens}

It is hypothesized that the endogenous estrogens produced in a non-pregnant young woman will exert very different physiological functions than those produced during pregnancy. This hypothesis is supported by the following evidence.

First, as discussed above, the endogenous estrogens formed in non-pregnant women are vastly different in quantity and composition from those produced in pregnant women.

Second, studies in recent years by us and by others have shown that some E2 derivatives can exert unique biological functions that are not shared by their parent hormone E2 (reviewed in refs. 6-8,14-16). For instance, a previous study showed that 4-OH-E2, a well-known hydroxylated metabolite of $\mathrm{E}_{2}$, has a far stronger blood cholesterol-lowering effect on rats than does E2 (16), although its uterotropic activity $(16,17)$ and ER-binding affinity are slightly lower than that of E2 $(5,17)$. Also, it is well documented that catechol estrogens are chemically reactive and potentially genotoxic/mutagenic, and it has been suggested that they play an important role in mediating hormonal carcinogenesis (18-20). In contrast, 2-methoxyestradiol, a non-polar endogenous E2 metabolite with little binding affinity for human ER $\alpha$ and ER $\beta$, has a strong anti-proliferative, anti-angiogenic and apoptotic effect $(7,21)$. It has been suggested that increased biosynthesis of this non-polar estrogen metabolite is highly beneficial for protection against estrogen-induced hormonal cancers $(7,15)$.

A previous study showed that E2 $15 \alpha$-hydroxylase activity, which catalyzes the formation of $15 \alpha-\mathrm{OH}-\mathrm{E}_{2}$ and $15 \alpha-\mathrm{OH}-\mathrm{E} 3$ (estetrol), was selectively elevated by 50 - to 70 -fold in a localized area of the uterine endometrium, where the imbedding of the fertilized ovum had taken place (22). Although the exact biological functions of the $15 \alpha-$ hydroxylated estrogens are not clear at present, it is likely that the formation of $15 \alpha-\mathrm{OH}-\mathrm{E}_{2}$ and $15 \alpha-\mathrm{OH}-\mathrm{E}_{3}$ (estetrol) may be involved in the imbedding process. Similarly, the amount of $15 \alpha$-hydroxylated estrogens present in the urine of a late-stage pregnant woman can be used as a reliable 
Table I. Comparison of daily urinary secretion (mean \pm SD) of endogenous estrogen metabolites during the pre-ovulatory phase, ovulation, and post-ovulatory phase of a normal non-pregnant woman with that of five pregnant women.

\begin{tabular}{|c|c|c|c|c|}
\hline \multirow[t]{2}{*}{ Estrogen } & \multicolumn{3}{|c|}{ Non-pregnant woman $(\mu \mathrm{g} / 24-\mathrm{h}$ urine $)$} & \multirow{2}{*}{$\begin{array}{l}\text { Pregnant women } \\
(\mu \mathrm{g} / 24-\mathrm{h} \text { urine })\end{array}$} \\
\hline & $\begin{array}{c}\text { Pre-ovulatory phase } \\
\text { (days 6-10) }\end{array}$ & $\begin{array}{l}\text { Ovulation } \\
\text { (day 0) }\end{array}$ & $\begin{array}{l}\text { Post-ovulatory phase } \\
\text { (days 6-10) }\end{array}$ & \\
\hline Estrone $\left(\mathrm{E}_{1}\right)$ & $6.2 \pm 3.9$ & $30.8 \pm 15.6$ & $16.2 \pm 12.4$ & $49.1 \pm 37.8$ \\
\hline 17ß-Estradiol (E2) & $0.9 \pm 0.8$ & $3.8 \pm 1.9$ & $1.6 \pm 0.2$ & $26.5 \pm 11.3$ \\
\hline 2-Hydroxyestrone (2-OH-E1) & $5.7 \pm 4.0$ & $22.5 \pm 12.0$ & $8.8 \pm 1.8$ & $22.1 \pm 11.4$ \\
\hline 4-Hydroxyestrone (4-OH-E1) & $0.7 \pm 0.4$ & $2.2 \pm 0.2$ & $1.1 \pm 0.3$ & $2.4 \pm 0.8$ \\
\hline $16 \alpha$-Hydroxyestrone $\left(16 \alpha-\mathrm{OH}-\mathrm{E}_{1}\right)$ & $2.4 \pm 1.5$ & $13.6 \pm 6.4$ & $5.0 \pm 3.3$ & $532.4 \pm 948.8$ \\
\hline 2-Methoxyestrone (2-MeO-E1) & $2.4 \pm 0.2$ & $0.5 \pm 0.8$ & $0.8 \pm 0.4$ & $6.9 \pm 3.4$ \\
\hline 2-Hydroxyestradiol (2-OH-E2) & $0.8 \pm 0.4$ & $1.8 \pm 1.2$ & $1.2 \pm 0.3$ & $3.4 \pm 3.6$ \\
\hline 4-Hydroxyestradiol (4-OH-E2) & ND & ND & ND & $0.5 \pm 0.1$ \\
\hline 2-Methoxyestradiol (2-MeO-E2) & ND & ND & ND & $11.5 \pm 14.5$ \\
\hline Estriol (E3) & $6.9 \pm 2.3$ & $28.8 \pm 12.2$ & $15.7 \pm 5.8$ & $11,174.8 \pm 9,304.3$ \\
\hline 16-Epiestriol (16-epi-E3) & ND & ND & ND & $562.3 \pm 626.3$ \\
\hline 17-Epiestriol (17-epi-E3) & ND & ND & ND & ND \\
\hline 16,17-Epiestriol $(16,17$-epi-E3) & ND & ND & ND & $176.7 \pm 72.2$ \\
\hline 2-Hydroxyestriol (2-OH-E3) & ND & ND & ND & $86.8 \pm 73.7$ \\
\hline 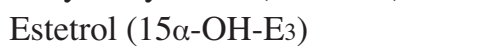 & ND & ND & ND & $302.0 \pm 273.3$ \\
\hline
\end{tabular}

The collection of human urine samples was approved by the Institutional Review Board. Urinary estrogens were determined using the GC/MS method, as described below. An aliquot $(1 \mathrm{ml})$ of the urine sample was transferred to a 1.5 -ml microcentrifuge tube containing $200 \mu 12 \mathrm{M} \mathrm{Na} \mathrm{AC}^{-}$ buffer ( $\mathrm{pH}$ 5.0), and the mixture was centrifuged at 14,000 rpm for $5 \mathrm{~min}$. The supernatant (1 ml) was transferred to a small glass tube containing $20 \mu \mathrm{l}$ of $0.5 \mu \mathrm{g} / \mu 1 \mathrm{E} 2-\mathrm{D} 2$ (in pure ethanol) as the internal standard, and $75 \mu 1 \mathrm{of} \mathrm{H}-2$ sulfatase as the enzyme for hydrolysis of estrogen conjugates. The reaction mixture was incubated at $37^{\circ} \mathrm{C}$ for $12 \mathrm{~h}$. After incubation, the tubes were centrifuged at $4,000 \mathrm{rpm}$ for $10 \mathrm{~min}$, and the supernatants were transferred to another set of test tubes and extracted with $5 \mathrm{ml}$ hexane/ethyl acetate (v:v, 3:2). The organic extracts were removed and dried under a stream of nitrogen gas. BSTFA $(100 \mu \mathrm{l})$ was added for derivatization at $65^{\circ} \mathrm{C}$ for $1 \mathrm{~h}$. The TMS derivatives of estrogen metabolites were detected using GC/MS. The GC/MS apparatus consisted of an Agilent 6890N GC with 7683 auto-sampler and an Agilent 5973 MS network, coupled with a HP-5MS capillary column. The front inlet temperature was $260^{\circ} \mathrm{C}$, and the column flow rate was $1.0 \mathrm{ml} / \mathrm{min}$. Oven temperatures were as follows: initial temperature was set at $180^{\circ} \mathrm{C}$, then increased by $4^{\circ} \mathrm{C} / \mathrm{min}$ to $260^{\circ} \mathrm{C}$. This temperature was kept constant for $5 \mathrm{~min}$, then further increased by $5^{\circ} \mathrm{C} / \mathrm{min}$ to $300^{\circ} \mathrm{C}$ and kept constant for $5 \mathrm{~min}$ at $300^{\circ} \mathrm{C}$ (with the $\mathrm{AUX}$ temperature at $280^{\circ} \mathrm{C}$ ). $\mathrm{ND}$, the estrogen metabolite of interest was not detected.

indicator of fetal well-being, and in particular of fetal lung functions (23-27).

Third, we recently studied the binding affinity of a large number of endogenous estrogen derivatives for human ER $\alpha$ and ERß (5). We found that the major estrogens present in non-pregnant young women had a clearly different preference for the activation of ER $\alpha$ over ERß, compared to the estrogens present in pregnant women. Some of the relevant data are briefly discussed below.

We found that $\mathrm{E}_{1}$ and 2-OH-E1, two of the quantitatively major estrogens present in non-pregnant women, had a modest but significant preference for binding to human ER $\alpha$ over ERß (5). E1 had a 3- to 4-fold higher preference for binding to human ER $\alpha$ than to ERß. Similarly, 2-OH-E1 (the 2-hydroxylated metabolite of $\mathrm{E}_{1}$ ) also had an $\sim 4$-fold preference for the activation of ER $\alpha$ over ERß. Notably, E1 and 2-OH-E1 had markedly lower binding affinity for human ER $\alpha$ and ERß compared to $\mathrm{E}_{2}$. It is reasonable to believe that the relatively lower binding affinity of $\mathrm{E}_{1}$ and 2-OH-E1 is actually an advantage rather than a disadvantage, because they pose a lower risk of causing over-stimulation of the ER $\alpha$ and ERß signaling systems in vivo.

On the other hand, E3, the quantitatively predominant estrogen produced during human pregnancy, had a significant preference for binding to ERß over ER $\alpha$ (5). Although E3 had a rather low binding affinity for human ER $\alpha$ compared to E2 (RBA $11 \%$ of $\mathrm{E}_{2}$ ), it retained a relatively high binding affinity for $\mathrm{ERB}$ (RBA $35 \%$ of $\mathrm{E}_{2}$ ). Therefore, $\mathrm{E}_{3}$ had an $\sim 3$ to 1 preference for binding to ERß over ER $\alpha$. Similarly, $16 \alpha-\mathrm{OH}-$ E1, another well-known hydroxylated metabolite of E1 that is formed in very large quantities during pregnancy, had a higher binding preference for ERß than ER $\alpha$ when compared to E1.

16,17-Epiestriol had a very low binding affinity for human $\mathrm{ER} \alpha$, but a preferential affinity for ERß; the difference in binding affinity for ERß over ER $\alpha$ was 18 -fold. Notably, this unique endogenous estrogen metabolite is usually undetectable in non-pregnant women, but is present at considerable levels during pregnancy (Table I).

In summary, it is evident that there is a distinct difference in the ratio and also intensity of ER $\alpha$ and ERß activation in 
non-pregnant young women compared to pregnant ones. The major estrogens produced in non-pregnant women modestly favor the activation of ER $\alpha$ over ERß. However, during pregnancy there is a preponderance of activation of ERß over ER $\alpha$ exerted by various pregnancy estrogens, in particular by $\mathrm{E}$ 3, which is produced in unusually large quantities. This preferential activation of ERß is believed to play an indispensable role in the mediation of the various actions of the endogenous estrogens that are likely required for the development of the fetus, as well as for fulfilling other physiological functions related to pregnancy such as the suppression of autoimmune response against the fetus. These suggestions are in line with observations that ERß has a wide distribution in maternal reproductive and lymphatic organs in rats, as well as in various tissues in the fetus (28-30).

\section{Biological activity of estrogens contained in Premarin}

Premarin, the most commonly used HRT, contains a mixture of conjugated estrogens isolated from pregnant mare's urine. The major estrogens produced in a pregnant mare are quite different from those produced in a pregnant woman and do not contain E3. However, they do contain a number of unique equine estrogens, many of which are basically not produced in humans. Our recent analysis showed that several of the equine estrogens contained in Premarin are functionally similar to the human pregnancy estrogen $\mathrm{E} 3$ with respect to their preferential binding affinity for human ERß over $\operatorname{ER} \alpha$ (5).

For example, while 17ß-dihydroequilenin had a low binding affinity for $\mathrm{ER} \alpha\left(35 \%\right.$ of $\left.\mathrm{E}_{2}\right)$, it had a high binding affinity for ERß (RBA $100 \%$ of E2). Equilin (i.e., 7-dehyroE1) had a decreased binding affinity for ER $\alpha$ compared to E1 (RBA $40 \%$ of $\mathrm{E}_{1}$ ) and a drastically increased affinity for ERB (RBA $631 \%$ of E1). Similarly, $D$-equilenin had a much weaker binding affinity than $\mathrm{E}_{1}$ for human $\mathrm{ER} \alpha$ (RBA $20 \%$ of E1), but its binding affinity for ERß was $>3$ times higher than that of E1.

All together, it is evident that many of the equine estrogens contained in Premarin have a strong differential binding affinity for human ERß over ER $\alpha$, which is very similar to the human pregnancy estrogen E3.

\section{Which estrogens are ideal for postmenopausal hormone replacement therapy?}

The risks and benefits of Prempro (Premarin + progestin) in healthy postmenopausal women were evaluated by following a total of 16,608 women, aged 50-79 years (average age, 63 at study intake) (31). In this study, one branch followed patients who received either a combination of equine estrogens plus a progestin $(8,506$ women $)$ or a placebo $(8,102$ women $)$ for 5.2 years. It was found that there was an increased risk of breast cancer with the use of Prempro. The risk of coronary artery disease, strokes and pulmonary embolism was increased as well. The study found that the measured risks of this combination outweighed its measured benefits. For women aged 50-59, there was an observed trend towards a reduced risk of cardiovascular disease (relative risk, $0.56 ; 95 \%$ confidence interval, 0.30-1.03). Similarly, results from other studies suggested that when equine estrogens were administered orally, liver functions were altered and the risk of blood clots was increased (32).

A previous study indicated that the adverse effects of oral conjugated equine estrogens may not be generalized to other estrogens (33). It appeared that while the conjugated equine estrogens were found to be associated with an increased risk of venous thrombosis, this risk was not associated with the use of esterified estrogen. Similarly, previous reports have suggested that the use of $17 \alpha$-ethynyl-estradiol contained in birth control pills appears to have different health effects on young women than does the use of equine estrogen-based HRT in postmenopausal women. It is not known whether the beneficial effect of $17 \alpha$-ethynyl-estradiol is due partly to its relatively higher preference for the human ER $\alpha$ over ERß as compared to equine estrogens.

It seems reasonable to suggest that an important empirical criterion that should be considered when an estrogen or a combination of estrogens is being evaluated for use in postmenopausal HRT is their ability to restore the hormonal environment to one found in normal non-pregnant young women, and not to one found in pregnant women. Since very different types of estrogens are produced in pregnant vs nonpregnant women and serve widely different physiological purposes, it is suggested that the use of endogenous estrogens found in non-pregnant young women will be more ideal for HRT than the use of estrogens predominantly produced during pregnancy. The former may include a combination of the sulfates of $\mathrm{E}_{1}$ and 2-OH-E1, and possibly other endogenous estrogens (such as the conjugates of 2-methoxyestrogens). The inclusion of methoxyestrogen sulfates in HRT may be beneficial because of 2-methoxyestradiol's strong antitumorigenic activity of $(7,15)$. Given that many endogenous estrogens may have rather rapid metabolic disposition in the body, some other naturally-occurring or synthetic estrogens with longer half-lives can also provide a similar preferential activation of the ER $\alpha$ system as $E_{1}$ and may be useful as alternatives. For instance, since $17 \alpha-\mathrm{E}_{2}$ has a similar ERbinding preference as $\mathrm{E}_{1}$ but cannot be converted to $\mathrm{E}_{2}$ by 17ß-hydroxysteroid dehydrogenase (17ß-HSD), the sulfate conjugates of $17 \alpha-E_{2}$ may serve as alternatives to E1-3-sulfate in order to achieve similar biological functions. In addition, our recent studies have shown that $17 \alpha-\mathrm{E}_{2}$ has a strong protective effect against neuronal cell death both in vitro and in vivo (unpublished data).

This would be a good time to suggest that using sulfated estrogens for human HRT would be better than using their corresponding parent estrogens. The main reasons are, first, the sulfated estrogens are themselves inactive (with little or no binding affinity for human ER $\alpha$ and ERß) (5), but can be enzymatically hydrolyzed to release bioactive estrogens in a variety of tissues in the body. Previous studies have shown that the estrogen target organs, such as the breast and uterus, contain much higher levels of estrogen sulfatase activity than other tissues (34-37). Second, oral administration of estrogen sulfates would provide a natural cushion effect by avoiding unwanted over-stimulation of the ER systems throughout the body. Instead, they would usually only activate those target tissues or cells most in need of estrogenic stimulation. Here, it is also worth noting that several recent studies have shown that estrogen target cells can actively transport E1-3-sulfate 
Differential Activation of the Human ER $\alpha$ and ER $\beta$

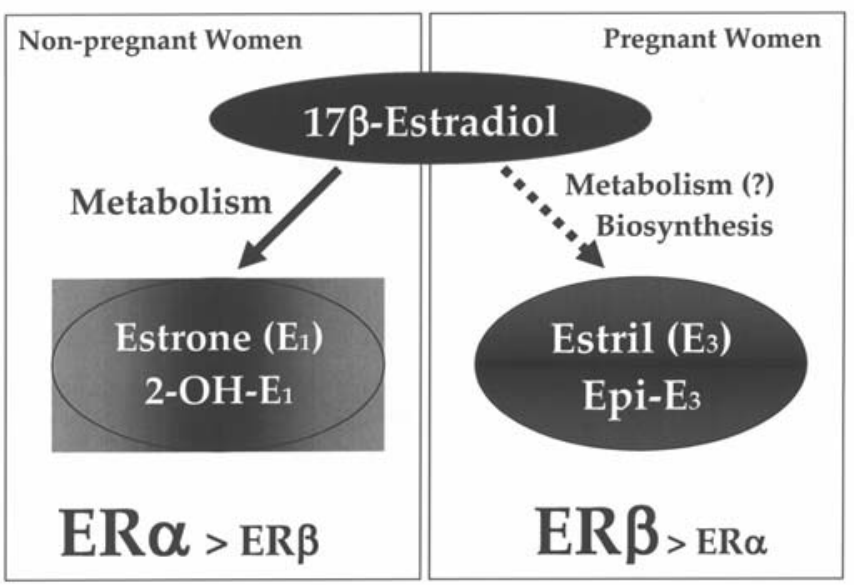

Figure 1. Differential activation of the human ER $\alpha$ and ERß in non-pregnant vs. pregnant women. In non-pregnant women, estrone $\left(E_{1}\right)$ is believed to be the major circulating estrogen. 17ß-Estradiol ( $\left.\mathrm{E}_{2}\right)$ biosynthesized in the body is quickly converted to $E_{1}$ by the $17 ß$-hydroxysteroid dehydrogenase (17ßHSD) present in various non-gonadal tissues, such as the liver. E1 has rather low binding affinity for $\mathrm{ER} \alpha$ and $\mathrm{ER} \beta$ compared to $\mathrm{E}_{2}$, but has a preferential binding affinity for ER $\alpha$ over ERß. 2-OH-E $\mathrm{E}_{1}$ is the major metabolite of $\mathrm{E}_{1}$ in vivo, and is also a very weak estrogen with a preference for ER $\alpha$ over ERß. It is therefore apparent that there is a preferential activation of the ER $\alpha$ system over the ERß system in non-pregnant women. In comparison, during pregnancy, the quantitatively predominant estrogens present in the circulation are estriol (E3) or 16 $\alpha-\mathrm{OH}-\mathrm{E} 1$, which are either metabolically formed from $16 \alpha$-hydroxylation of endogenous estrogens (such as $E_{2}$ or $E_{1}$ ), or via other bio-synthetic pathways in the feto-placental unit. Both of these estrogens, which are formed in relatively small quantities in non-pregnant women, have a preferential binding affinity for ERß over ER $\alpha$. Therefore, there is a clear difference in the ER activation profiles of non-pregnant vs. pregnant women. For hormone replacement therapy (HRT), the ideal situation is to mimic the hormonal status of non-pregnant healthy young women instead of that of pregnant ones. The current HRT, with its use of Premarin, largely mimics the hormonal conditions of a pregnant woman because, as our recent study (5) showed, many of the estrogens contained in Premarin (isolated from pregnant mare's urine) produce a preferential stimulation of human ERß over $\mathrm{ER} \alpha$.

into the cells $(38,39)$. Moreover, these cells may selectively adjust their ability to actively transport E1-3-sulfate into the cells to release biologically active estrogens depending on their hormonal needs. Theoretically, such a mechanism would offer certain degrees of target organ selectivity of estrogenic stimulation. Third, compared to estrogen glucuronides, estrogen sulfates are probably better because they usually have a lower clearance rate and a longer half-life $\left(\mathrm{T}_{1 / 2}\right)$ in humans, thereby making them pharmacologically more useful $(40,41)$.

Based on the above discussion, it is suggested that the use of estrogens to produce a modest level of stimulation of both the ER $\alpha$ and ERß systems, with a slight preference for the ER $\alpha$ system, would be better for postmenopausal HRT than the use of estrogens that confer a predominant activation of the ERß system. It is apparent that Premarin, the most widely prescribed HRT, may not be the most suitable combination of estrogens for achieving this clinical purpose. Notably, while there is a considerable amount of E1-3-sulfate contained in Premarin, which presumably is good for its intended purpose as an HRT, the fact is that it also contains many other very potent equine pregnancy estrogens which, jointly, result in a strong overstimulation of the ERß system. Similarly, genistein, a potent and preferential partial agonist of human ERß, would be even less suitable than Premarin for use as postmenopausal HRT because it would essentially produce a near selective ERß stimulation. This is in agreement with recent clinical observations, showing that the singular use of genistein is mostly ineffective as an HRT in postmenopausal women $(42,43)$.

\section{Concluding remarks}

Until recently, the general scientific belief has been that all estrogens exert the same or highly similar pharmacological actions on a woman's body. When the oral tablet of Premarin was first approved by the U.S. Food and Drug Administration (FDA) for human use in 1942, its $0.625 \mathrm{mg}$ dosage (still in use today) was actually assigned solely on the basis of its estrogenic potency in a rat bioassay that was found to be equivalent to $0.625 \mathrm{mg}$ of sodium E1-3-sulfate. This bioassay mostly measured the ER $\alpha$-mediated uterotropic activity. Even to this day, little is known about the precise hormonal strength of Premarin and each of the bioactive components for human $\mathrm{ER} \alpha$ and ERß systems.

As discussed above, although $\mathrm{E}_{2}$ is among the most potent endogenous estrogens and has almost equal binding affinity for human $E R \alpha$ and $E R \beta$, it is not one of the major estrogens present in women. In fact, $\mathrm{E}_{1}$ or $\mathrm{E}_{3}$, depending on the physiological conditions, are the quantitatively major estrogens present. Although their binding affinities for ER $\alpha$ and ERß are lower than those of E2, they provide a differential activation of the ER $\alpha$ or ERß signaling system. Our recent study showed that endogenous estrogens (such as $\mathrm{E}_{1}$ and 2-OH-E1) present in non-pregnant women mainly activate the ER $\alpha$ system, whereas estrogens (such as E3 and epi-E3) present in pregnant women predominantly activate the ERß system. Therefore, the facile metabolic conversion of $E_{2}$ to $E_{1}$ or of $E_{2}$ to $E_{3}$ in women provides an important means of achieving differential activation of the ER $\alpha$ or ERß signaling system under different physiological conditions. This concept is summarized in Fig. 1.

It is reasonable to suggest that the estrogens most suitable for human HRT would be those that can mimic the physiological estrogenic stimulation of premenopausal non-pregnant women, and not that of pregnant women. Based on this new concept, it appears that naturally-occurring estrogens like E1 and E1-3-sulfate would be more suitable for use as postmenopausal HRT than Premarin, essentially composed of pregnancy estrogens (with a strong preference for ERß). It is apparent that a balanced activation of the ER $\alpha$ and ERß systems, with a modest preference for the ER $\alpha$ system, would be better for HRT, compared to estrogens that predominantly activate the ERß system. It is believed that an optimallyadjusted activation of the ER $\alpha$ and ERß signaling systems would help maximize the beneficial effects of HRT, and additionally minimize its untoward effects.

\section{References}

1. Nilsson S and Gustafsson JA: Estrogen receptor action. Crit Rev Eukaryot Gene Expr 12: 237-257, 2002

2. Carpenter KD and Korach KS: Potential biological functions emerging from the different estrogen receptors. Ann NY Acad Sci 1092: 361-373, 2006.

3. Jordan VC: SERMs: meeting the promise of multifunctional medicines. J Natl Cancer Inst 99: 350-356, 2007. 
4. Jordan VC: Chemoprevention of breast cancer with selective oestrogen-receptor modulators. Nat Rev Cancer 7: 46-53, 2007.

5. Zhu BT, Han GZ, Shim JY, Wen Y and Jiang XR: Quantitative structure-activity relationship (QSAR) of various endogenous estrogen metabolites for human estrogen receptor $\alpha$ and $B$ subtypes: insights into the structural determinants favoring a differential subtype binding. Endocrinology 147: 4132-4150, 2006.

6. Zhu BT and Conney AH: Functional role of estrogen metabolism in target cells: review and perspectives. Carcinogenesis 19: 1-27, 1998.

7. Zhu BT and Conney AH: Is 2-methoxyestradiol an endogenous estrogen metabolite that inhibits mammary carcinogenesis? Cancer Res 58: 2269-2277, 1998.

8. Weisz J: Metabolism of estrogens by target cells: diversification and amplification of hormone action and the catechol estrogen hypothesis. In: New Biology of Steroid Hormones. Hochberg RB and Naftolin F (eds). Raven Press, New York, pp101-112, 1991.

9. Fotsis T and Adlercreutz H: The multicomponent analysis of estrogens in urine by ion exchange chromatography and GC-MS-I. Quantitation of estrogens after initial hydrolysis of conjugates. J Steroid Biochem 28: 203-213, 1987.

10. Fotsis T: The multicomponent analysis of estrogens in urine by ion exchange chromatography and GC-MS-II. Fractionation and quantitation of the main groups of estrogen conjugates. J Steroid Biochem 28: 215-226, 1987.

11. Lee AJ, Cai MX, Thomas PE, Conney AH and Zhu BT: Characterization of the oxidative metabolites of 17ß-estradiol and estrone formed by fifteen selectively expressed human cytochrome P450 isoforms. Endocrinology 144: 3382-3398, 2003.

12. Lee AJ, Kosh JW, Conney AH and Zhu BT: Characterization of the NADPH-dependent metabolism of 173 -estradiol to multiple metabolites by human liver microsomes and selectively expressed human cytochrome P450 3A4 and 3A5. J Pharmacol Exp Ther 298: 420-432, 2001.

13. Lee AJ, Mills LH, Kosh JW, Conney AH and Zhu BT: NADPHdependent metabolism of estrone by human liver microsomes. J Pharmacol Exp Ther 300: 838-849, 2002.

14. Zhu BT and Lee AJ: NADPH-dependent metabolism of 17ßestradiol and estrone to polar and nonpolar metabolites by human tissues and cytochrome P450 isoforms. Steroids 70: 225-244, 2005.

15. Zhu BT: Catechol- $O$-methyltransferase (COMT)-mediated methylation metabolism of endogenous bioactive catechols and modulation by endobiotics and xenobiotics: Importance in pathophysiology and pathogenesis. Curr Drug Metab 3: 321-349, 2002.

16. Liu D and Bachmann KA: An investigation of the relationship between estrogen, estrogen metabolites and blood cholesterol levels in ovariectomized rats. J Pharmacol Exp Ther 286: 561-568, 1998.

17. Ball P and Knuppen R: Catecholoestrogens (2- and 4-hydroxyoestrogens): chemistry, biogenesis, metabolism, occurrence and physiological significance. Acta Endocrinol 232: 1-127, 1980.

18. Liehr JG: Is estradiol a genotoxic mutagenic carcinogen? Endocr Rev 21: 40-54, 2000

19. Cavalieri E, Frenkel K, Liehr JG, Rogan E and Roy D: Estrogens as endogenous genotoxic agents - DNA adducts and mutations. J Natl Cancer Inst Monogr 27: 75-93, 2000.

20. Yager JD and Davidson NE: Estrogen carcinogenesis in breast cancer. N Engl J Med 354: 270-282, 2006.

21. Sutherland TE, Anderson RL, Hughes RA, Altmann E, Schuliga M, Ziogas J and Stewart AG: 2-Methoxyestradiol - a unique blend of activities generating a new class of antitumour/anti-inflammatory agents. Drug Discov Today 12: 577-584, 2007.

22. Chakraborty C, Davis DL and Dey SK: Estradiol-15 $\alpha-$ hydroxylation: a new avenue of estrogen metabolism in periimplantation pig blastocysts. J Steroid Biochem 35: 209-218, 1990.

23. Tulchinsky D, Frigoletto FD Jr, Ryan KJ and Fishman J: Plasma estetrol as an index of fetal well-being. J Clin Endocrinol Metab 40: $560-567,1975$.
24. Kundu N and Grant M: Radioimmunoassay of $15 \alpha$-hydroxyestriol (estetrol) in pregnancy serum. Steroids 27: 785-796, 1976.

25. Notation $\mathrm{AD}$ and Tagatz GE: Unconjugated estriol and $15 \alpha-$ hydroxyestriol in complicated pregnancies. Am J Obstet Gynecol 128: 747-756, 1977

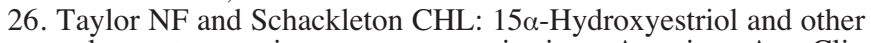
polar oestrogens in pregnancy monitoring - A review. Ann Clin Biochem 15: 1-11, 1978.

27. Kunda N, Wachs M, Iverson G and Petersen LP: Comparison of serum unconjugated estriol and estetrol in normal and complicated pregnancies. Obstet Gynecol 58: 276-281, 1981.

28. Saunders FJ: Effects of sex steroids and related compounds on pregnancy and on development of the young. Physiol Rev 48: 601-643, 1968.

29. Hewitt SC and Korach KS: Oestrogen receptor knockout mice: Roles for oestrogen receptors $\alpha$ and $\beta$ in reproductive tissues. Reproduction 125: 143-149, 2003.

30. Lemmen JG, Broekhof JL, Kuiper GG, Gustafsson J-A, van der Saag PT and van der Burg B: Expression of estrogen receptor $\alpha$ and $\beta$ during mouse embryogenesis. Mech Dev 81: 163-167, 1999.

31. Rossouw JE, Anderson GL, Prentice RL, LaCroix AZ, Kooperberg C, Stefanick ML, Jackson RD, Beresford SA, Howard BV, Johnson KC, Kotchen JM, Ockene J and Writing Group for the Women's Health Initiative Investigators: Risks and benefits of estrogen plus progestin in healthy postmenopausal women: principal results from the Women's Health Initiative randomized controlled trial. JAMA 288: 321-333, 2002.

32. Scarabin PY, Oger E, Plu-Bureau G and Estrogen and Thromboembolism Risk Study Group: Differential association of oral and transdermal oestrogen-replacement therapy with venous thromboembolism risk. Lancet 362: 428-432, 2003

33. Smith NL, Heckbert SR, Lemaitre RN, Reiner AP, Lumley T, Weiss NS, Larson EB, Rosendaal FR and Psaty BM: Esterified estrogens and conjugated equine estrogens and the risk of venous thrombosis. JAMA 292: 1581-1587, 2004.

34. Hobbirk R: Steroid sulfotransferases and steroid sulfate sulfatases: Characteristics and biological roles. Can J Biochem Cell Biol 63: 1127-1144, 1985 .

35. Santner SJ, Feil PD and Santen RJ: In situ estrogen production via the estrone sulfatase pathway in breast tumors: relative importance versus the aromatase pathway. J Clin Endocrinol Metab 59: 29-33, 1984.

36. MacIndoe JH, Woods G, Jeffries L and Hinkhouse M: The hydrolysis of estrone sulfate and dehydroepiandrosterone sulfate by MCF-7 human breast cancer cells. Endocrinology 123: 1281-1287, 1988.

37. Pasqualini JR, Gelly C, Nguyen B-L and Vella C: Importance of estrogen sulfates in breast cancer. J Steroid Biochem 34: 155-163, 1989 .

38. Miki Y, Suzuki T, Kitada K, Yabuki N, Shibuya R, Moriya T, Ishida T, Ohuchi N, Blumberg B and Sasano H: Expression of the steroid and xenobiotic receptor and its possible target gene, organic anion transporting polypeptide- $\mathrm{A}$, in human breast carcinoma. Cancer Res 66: 535-542, 2006.

39. Nozawa T, Suzuki M, Takahashi K, Yabuuchi H, Maeda T, Tsuji A and Tamai I: Involvement of estrone-3-sulfate transporters in proliferation of hormone-dependent breast cancer cells. J Pharmacol Exp Ther 311: 1032-1037, 2004.

40. Twombly GH and Levitz M: Metabolism of estrone- $\mathrm{C}^{14}-16$ sulfate in women. Am J Obstet Gynecol 80: 889-898, 1960.

41. Ruder HJ, Loriaux L and Lipsett MB: Estrone sulfate: production rate and metabolism in man. J Clin Invest 51: 1020-1033, 1972.

42. Fitzpatrick LA: Soy isoflavones: Hope or hype? Maturitas 44 (Suppl 1): 21-29, 2003.

43. Rozman KK, Bhatia J, Calafat AM, Chambers C, Culty M, Etzel RA, Flaws JA, Hansen DK, Hoyer PB, Jeffery EH, Kesner JS, Marty S, Thomas JA and Umbach D: NTP-CERHR expert panel report on the reproductive and developmental toxicity of genistein. Birth Defects Res B Dev Reprod Toxicol 77: 485-638, 2006. 